\title{
SOME NEW NEARCTIC COLLEMBOLA
}

\author{
By D. L. Wray \\ Raleigh, N. C.
}

The insect order Collembola seems to have as extensive geographical distribution as any other animal group. Many species are very widely distributed geographically, but some are limited to particular ecological situations. A few years ago I described Tetracanthella ethelae taken here at Raleigh, N. C., at an altitude of only 325 feet. The habitat of this genus was the Arctic regions of North America and the higher mountainous regions of Europe and Asia. This past year $T$. ethelae was taken near the top of Mt. Mitchell, at an altitude of about 6500 feet and up on the side of Grandfather Mt. at an altitude of about 5000 feet. Hence here is a species with a wide range as to both altitude and geographical distribution. Recently in some material sent to me for study by Dr. G. F. Knowlton from Utah I found a Tullbergia having three anal horns, a form very close to the European $T$. affinis Börner. Bonet (1944) has described a form (Mesaphorura incisa) with three anal horns from Mexico. Of particular interest is the occurrence of another European form (Xenyllodes armatus Axels.) in North America fauna. A note on this species is given below.

The forms described in this paper are Tullbergia knoweltoni (Onychiurinae), Onychiurus reilchi (Onychiurinae), and Folsomia highlandia (Isotominae).

Family ENtomobryidae.

Genus Folsomia Willem.

\section{Folsomia highlandia, n. sp.}

(Figs. 10-17)

Length up to $1.8 \mathrm{~mm}$. Dirty gray in color, speckled with purplishblack pigment over head and body segments dorsally and ventrally. The pigment is noticeably heavy on the frontal area of the head (Fig. 16). The pigment on the body segments is heavier on the 
median portion, each margin lightly pigmented, or with it entirely lacking, giving the body a banded appearance. Antennae slightly pigmented basally, lighter distally. Basal segments of legs pigmented, lighter distally. Manubrium lightly pigmented basally.

Eyes (Fig. 13) 4 on each side of head, equal, three anterior ones close together on a dark eye patch, the posterior one is situated back of others about 4 eye-diameters on a dark eye-patch. Postantennal organ (Fig. 13) unusually elongate, bent, and 6 or 7 times as long as the diameter of adjacent eye, notched in middle. Antennae as long as head on well developed antennal base. Antennal segments as: 7:15: 10:30. Sense organ of third antennal segment (Fig. 11) consisting of two small, slightly bent sense rods. Fourth antennal segment with several olfactory setae. Last three abdominal segments ankylosed, sometimes with a trace of a suture showing between fourth and fifth segments.

Unguis (Fig. 10) curved, unarmed. Unguiculus (Fig. 10) unarmed, broadly lanceolate, and extended setaceously; about twothirds the length of unguis. Tenent hairs absent. Furcula reaching to the middle of the second abdominal segment. Manubrium (Fig. 12) with several fine, short setae dorsally and with many short, stout setae ventrally. Manubrium to dens to mucro as: 25:35:5. Dentes (Fig. 15) with a long basal seta and at least 3 shorter, curving setae dorsally; with many short, rather stout setae ventrally; dorsally crenulate, the crenulations ending about two mucro-lengths from mucro. Mucro (Fig. 15) large, bidentate, the apical tooth much smaller than ante-apical. Rami of tenaculum quadridentate, with one stout, curving seta on corpus (Fig. 14).

Clothing at posterior end of abdomen composed of very many long setae intermingled with shorter, curving ones. Clothing on body segments (Fig. 17), from a lateral view, generally consists of two long, curved setae, and numerous shorter, reclinate ones. Body in general unusually heavily clothed with setae.

This species is very close to an eight-eyed species (Folsomia octoculata Handschin) described from Java and the South-west provinces of India, as to number and arrangement of eyes, but differs in other body structures.

Highlands, N. C., September 22, 1949, D. L. Wray. Eighteen specimens were taken from leaf mould from a mixed pine, hemlock, and hardwood forest at about 4000 feet altitude. This region stays 
rather moist due to the very heavy yearly rainfall making it ideal for collembolan fauna. Cotypes in author's collection.

Family Poduridae.

Genus Tullbergia Lubbock.

\section{Tullbergia (Mesaphorura) knowltoni, n. sp.}

(Figs. 1-9)

Length up to $0.7 \mathrm{~mm}$. White. Slender (Fig. 1), body five times as long as broad. Antennae short, two-thirds as long as head, the third and fourth segments not distinctly separated. Relative lengths of antennal segments as: $3: 4: 6: 5$. Antennal base well developed. Fourth antennal segment with a terminal sense knob and with 6 to 8 large, curving olfactory setae (Fig. 4). Organ of third antennal segment (Fig. 5) with three guard setae, two large sub-reniform sense clubs, curving toward each other, and two large papillae shielding the sense clubs; ventro-laterally to these is an auxilliary sense club. Postantennal organ in an elongated groove, with about 24-28 irregular tubercles (Fig. 3), somewhat shaped like the Onychiurus fimetarius group postantennal organ. Pseudocelli, rosettelike, situated on each side as follows: 1 between postantennal organ and base of antenna, 1 on posterior part of head, 1 on mesothorax and metathorax, and with 1 on abdominal segments I-V, wanting on abdominal segment VI.

Unguis (Fig. 8) unarmed. Unguiculus absent. Anal horns (Fig. 7) 3 ; two long, strongly curved ones about twice the length of the hind unguis are situated on the postero-dorsal end of body on large nearly contiguous papillae; the third horn is short, bluntly rounded at apex, in length about half the unguis, and is situated mid-ventral to the pair above.

Body with short backward curving setae in three rows on mesothorax to abdominal segment $V$. Longer setae intermingled in one row on each segment and are more abundant on head and 5th and 6 th abdominal segments. The 6 th abdominal segment with two rows of long curving setae. Integument granulate, becoming coarser dorsally on the posterior margin of thorax II to abdominal segment V.

Logan, Utah, October 31, 1949, G. F. Knowlton and S. C. Ma. Taken in honeysuckle leaves by means of a modified Berlese funnel. Cotypes at present in author's collection. 
This species is very close to Tullbergia affinis Börner in the arrangement and size of the 3 anal horns, but differs in that pseudocelli were not observed on thorax I, the unguiculus was not distinguished, the size is smaller, and there seems to be differences in the organ of the $3 \mathrm{rd}$ antennal segment and postantennal organ.

\section{Genus Onychiurus Gervais.}

\section{Onychiurus wilchi, n. sp.}

(Figs. 18-25)

Length up to $1.5 \mathrm{~mm}$. White. Postantennal organ (Fig. 20) of the fimetarius type, each with 18-20 branched tubercles placed at right angles to the long axis. Antennae shorter than the head, with the antennal segments in the following proportions: 7:13:15:17. Organ of the third antennal segment (Fig. 19) with 5 papillae, 5 guard setae, 2 sense rods, and 2 sense clubs. Fourth antennal segment with 10-12 curving olfactory hairs. Pseudocelli (Fig. 18) on each side as follows: 2 on inner side of antennal base and one between antennal base and postantennal organ; 2 obliquely situated on back of head; meso- and meta-thorax 2; 2nd and 3rd abdominal 2 ; 4th and 5 th abdominal 3 . One pseudocellus on each precoxal.

Unguis (Fig. 21) stout, curving, unarmed. Unguiculus unarmed, slender, gradually tapering to apex which is extended in the form of a fine filament to length of unguis. Anal spines 2 (Fig. 23), stout, and almost straight, bases widely separated; two-thirds as long as hind unguis. Long curving setae at posterior end of abdomen. Clothing of scattered long straight setae, sparse short setae, and a few minute strongly curved setae (Fig. 24). Cuticular tubercles (Fig. 23) coarse.

Highland, Illinois June 7, 1946, B. T. Wilch. This species is named for Mr. B. T. Wilch who collected fifteen specimens from garden soil, and which were transmitted to me for study by Dr. H. H. Ross, of the Illinois Natural History Survey, with whom most of the cotypes will be deposited.

\section{Genus Xenyllodes Axelson, 1903.}

Eyes 5 on each side of head. Postantennal organ consisting of a single, trilobed tubercle. Antennae with broad basal segments, 
almost touching, distally segments become conical. Mouthparts reduced. Unguis unarmed. Unguiculus present. Furcula shorter than antennae; manubrium slightly longer than dens, which is slightly longer than mucro. Anal horns 2. Integument finely granulated. Body short, thick, length up to $1 \mathrm{~mm}$.

\section{Xenyllodes armatus Axelson 1903.}

(Figs. 26-30)

This form from Raleigh, N. C., collected from leaf mould has been referred to this species as it agrees very well in most essential characters with the description given by Axelson (1912), and also with that by Dr. Jan Stach (1949). However, it does vary in some characters, such as the length of the anal horns, postantennal organ, and furcula measurements, from the illustrations given by Axelson. This is probably the first time this genus has been recorded as occurring in North America. The form from here has been examined by Dr. H. B. Mills, Illinois Natural History Survey, and credit is given him as first recognizing this form as occurring in North America as he states that he found it in Montana, previously to the ones I sent from this locality. As far as we are aware this genus has not been in North American literature as yet. Dr. Jan Stach (1949) states that till now this species is only known from Europe. Thus, this is an interesting extension of the range of this genus and as with other genera, when more intensive collecting is done, one may expect or not be surprised to find an ever widening geographical distribution.

Description of North Carolina form. Eyes 5 (Fig. 26) on each side of head, equal in size on a dark eyepatch. Postantennal organ consisting of a single, trilobed tubercle with a round "central organ"; situated in a depression close to front of the eye complex (Fig. 26). Antennae with broad basal segments, almost touching, distally segments become conical (Fig. 27); shorter than head, relative lengths of segments as : $3: 5: 5: 8$. Fourth antennal segment with a rounded lobe at tip, and with 5 or 6 olfactory hairs. Mouthparts reduced. Unguis (Fig. 28) unarmed. Unguiculus present but weakly developed, small, spinnate. Furcula well developed, shorter than antennae; manubrium slightly longer than dens, which is slightly longer than mucro (Fig. 30). Anal horns 2, very small but well developed (Fig. 29). Integument finely granulate. Clothing of 
short, curving setae; posterior end of abdomen with longer curving setae (Fig. 29). Length $0.4 \mathrm{~mm}$. White with bluish tinge mainly on head.

I wish to express my many thanks and appreciation to Dr. G. F. Knowlton and Mr. S. C. Ma for material from Utah, to Dr. H. B. Mills for his notes on Xenyllodes, to Dr. H. H. Ross for material from Illinois, and to Dr. Hermann Gisin, Genève, Switzerland, for making available specimens of Tullbergia affinis Börner from Europe.

\section{Explanation of Plate 5}

Tullbergia knowltoni, n. sp. (Figs. 1-9) 1. Dorsal view of the whole animal. 2. Ocellus. 3. Postantennal organ. 4. Tip of fourth antennal segment. 5. Organ of third antennal segment. 6. Mandible. 7. Posterior end of abdomen showing anal horns. 8. Unguis. 9. Ventral view of posterior end of abdomen. Folsomia highlandia, n. sp. (Figs. 10-17) 10. Hind foot. 11. Organ of third antennal segment. 12. Dorsal surface of manubrium. 13. Eyes and postantennal organ. 14. Tenaculum. 15. Dens-mucro 15. Dorsal surface of head. 17. Pigmentation of body segment, dorsal surface scheme. Onychiurus wilchi, n. sp. (Figs. 18-25) 18. Dorsal view of whole animal. 19. Organ of third antennal segment. 20. Postantennal organ. 21. Hind foot. 22. Ocellus. 23. Anal horn. 24. Clothing arrangement of setae. 25. Mandible. Xenyllodes armatus Axelson. (Figs. 26-30) 26. Eyes and postantennal organ. 27. Antenna showing round knob at tip. 28. Hind foot. 29. Posterior end of body, dorsal view, showing anal horns. 30. Densmucro. 


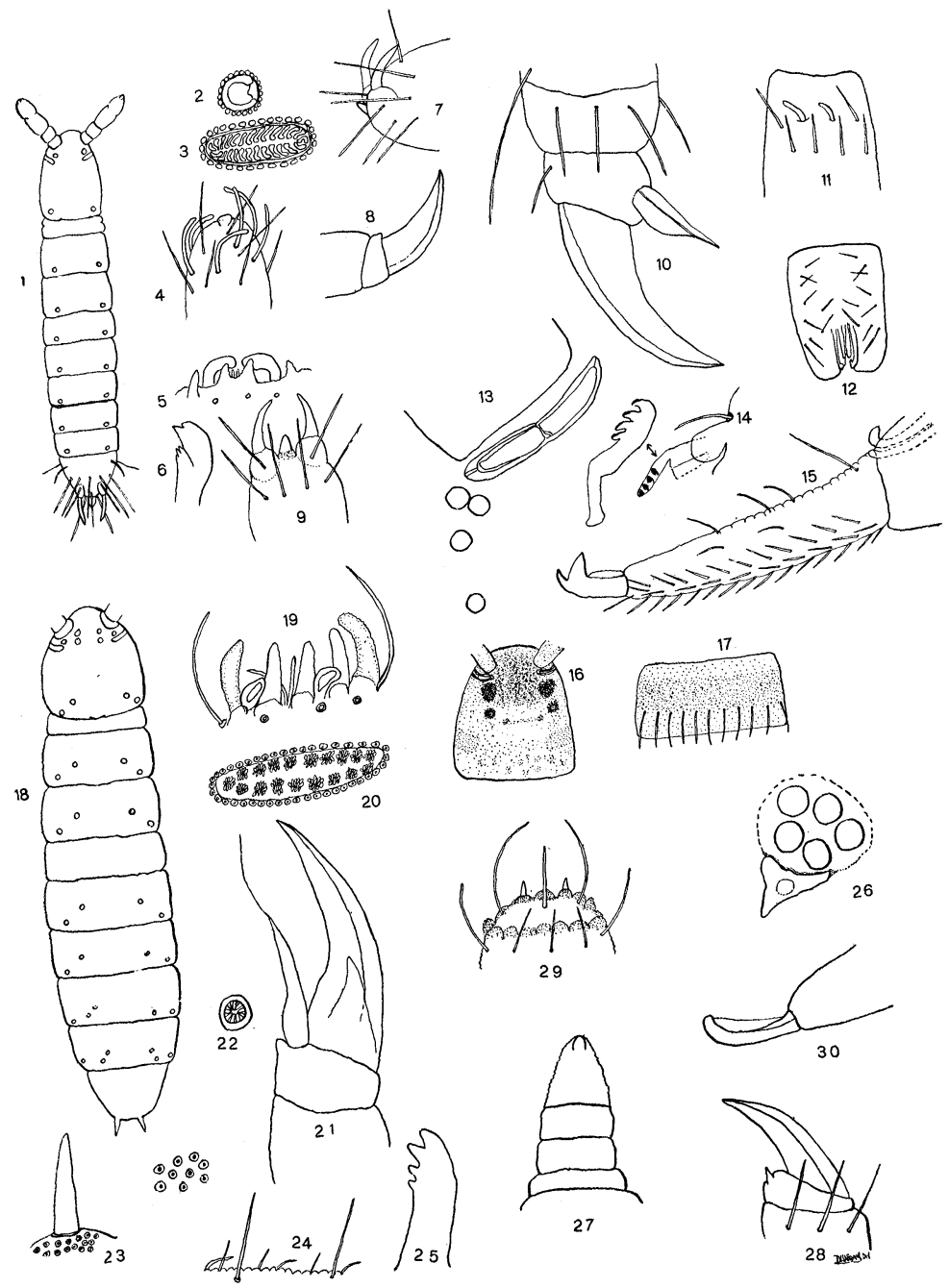



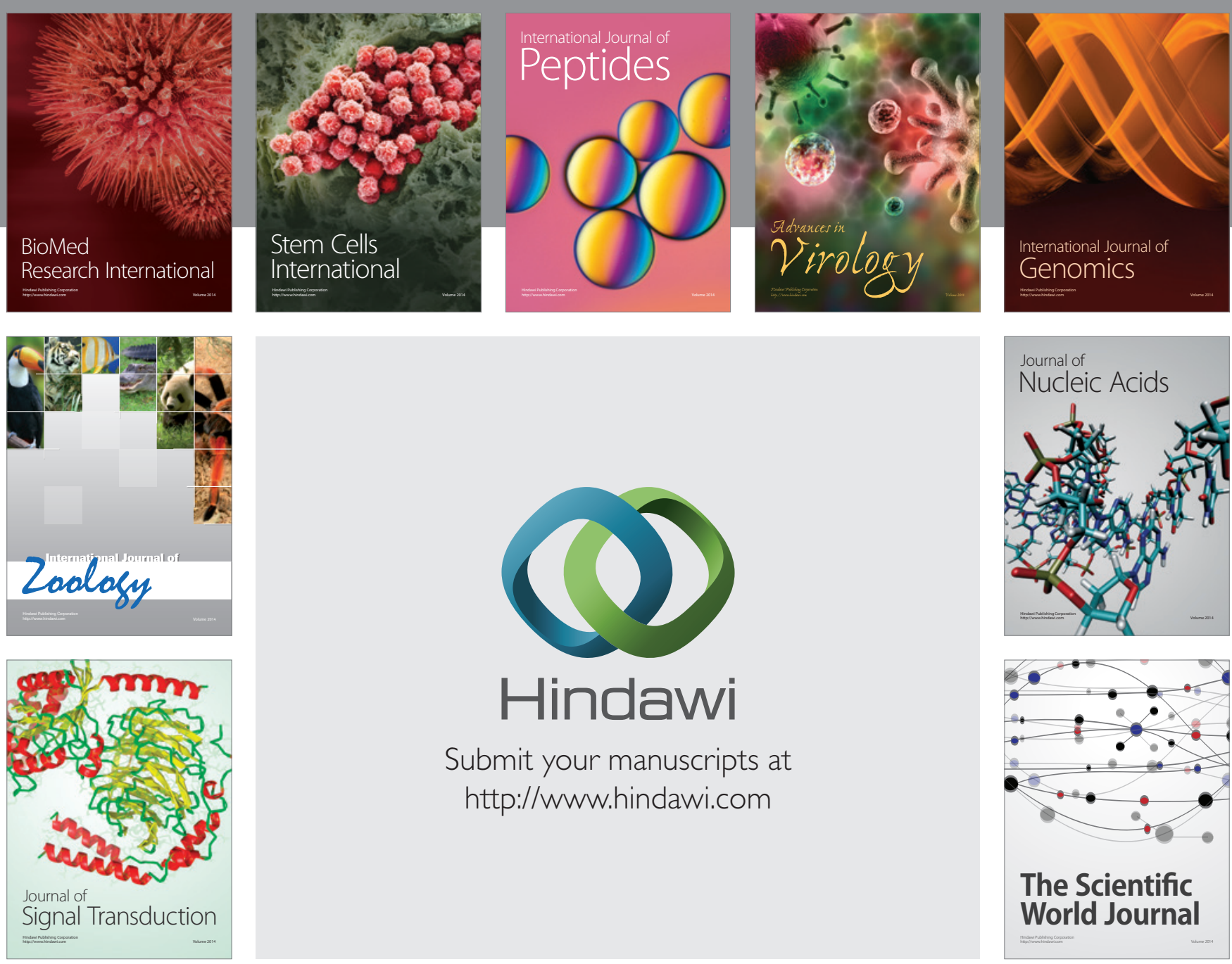

Submit your manuscripts at

http://www.hindawi.com
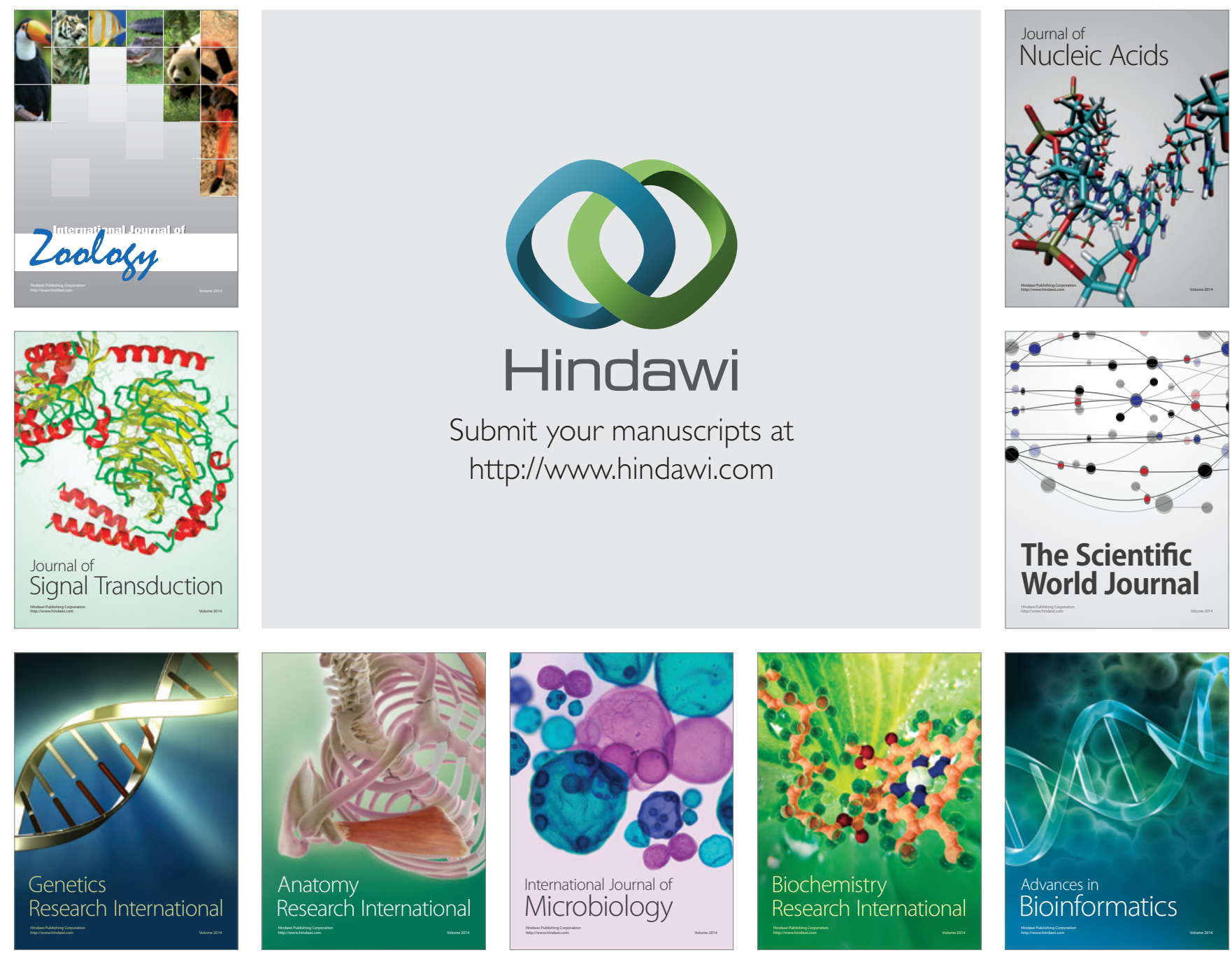

The Scientific World Journal
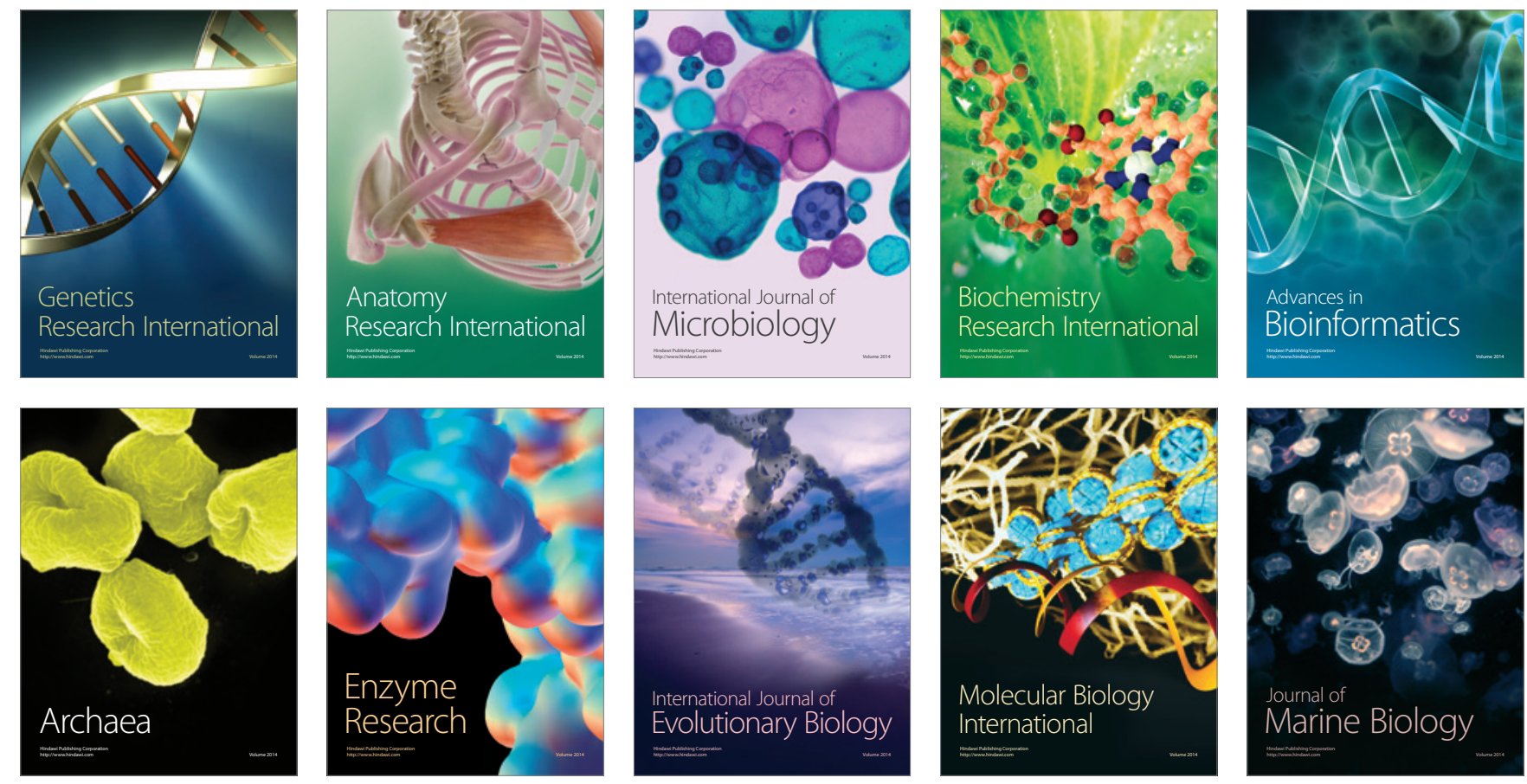